\title{
Stem cells to replace the optic nerve
}

\begin{abstract}
Methods that exist now and that might be developed are suggested to replace retinal ganglion cells and their axons in the optic nerve, ultimately to re-establish functional vision in eyes blind from glaucoma.
\end{abstract}

Eye (2004) 18, 1085-1088. doi:10.1038/sj.eye.6701577

Keywords: glaucoma; retinal ganglion cells; stem cells; regeneration

\section{Introduction}

Clearly, the best way to improve the quality of life of those at risk for glaucoma is to prevent the onset of their disease. This could be achieved by identification of the population at risk, surveillance of their initial damage, and preventive treatment before vision is lost. However, in the real world, these methods either do not yet exist, or those that could be applied are imperfectly used. As a result, we will be faced for the foreseeable future with persons whose vision is now irretrievably lost due to death of retinal ganglion cells (RGC). I am personally grieved each time that I must tell another person: 'Once damage has occurred from glaucoma, there is nothing we can do to replace it'.

Nearly 10 years ago, I convened a small group of interested researchers with the aim to discuss a futuristic goal - the regeneration of the human optic nerve in an eye blind from glaucoma. At that time, embryonic stem cells from human fetuses were being generated in the laboratory of John Gearhart at Johns Hopkins and there was considerable ferment both scientifically and ethically about the potential of these newly derived cell lines. We discussed the barriers that prevent the restoration of vision in an eye blind from loss of RGC. We evaluated the available tools to surmount those barriers. We made a list of several dozen steps that would need solution.

Today, we have already achieved solutions for some of these problems in animal model
HA Quigley and DS Iglesia

systems, and the overall goal appears

increasingly feasible. This brief summary will enumerate one possible set of directions for the recipe to make a new optic nerve.

\section{Steps towards restoring the optic nerve}

\section{Sources of new tissue}

Initially, the source of cells for a new optic nerve was thought to be embryonic or fetal tissue. Embryonic stem cells and germline cells ${ }^{1}$ had just been described and there was a possibility that these could be directed towards neural lineage and multiplied to provide the numbers needed. There were many difficulties, not least the ethical issue and the US government ban on stem cell work under NIH funding.

A second source would be embryonic retinal ganglion cells, ${ }^{2}$ dissociated from the developing retina. These have been used in a variety of experiments in vitro and have the advantage that they are already committed to becoming RGC. The number that could be expected from one fetal eye would be up to 3 million in a human. It would be critical to determine the appropriate timing, since, ideally, it would be best to obtain the RGC prior to their sending an axon from the eye.

Lund and Hankin ${ }^{3}$ have studied transplants of whole fetal retina. This has the advantage that the entire retinal architecture including all its layers would be transplanted intact. However, the small size of such transplants would limit the ultimate field of view.

All three of these first choices, though intriguing, seemed problematic due to the ethical issues of removing cells or ocular tissue from human fetuses. In addition, it would have to be presumed that immune rejection would be an issue (unless the fetus were a clone of the recipient). It has been suggested that the eye has certain immune privileges, especially that in the anterior chamber. ${ }^{4}$ The subretinal space also has been considered somewhat privileged. Nonetheless, an eye diseased from glaucoma that undergoes injections into its posterior
Glaucoma Service and the Dana Center for Preventive Ophthalmology Wilmer Ophthalmological Institute

Johns Hopkins University School of Medicine Baltimore MD, USA

\section{Correspondence:} HA Quigley

Glaucoma Service and the Dana Center for Preventive Ophthalmology

The Johns Hopkins

University

720 Rutland Avenue

Baltimore, MD 21205, USA

Received: 4 September 2003

Accepted in revised form: 4 September 2003

Supported in part by PHS Research Grant 02120 from the National Eye Institute, National Institutes of Health, Bethesda, MD, USA, and by the Wagner Charitable Trust, New York, NY, USA 
compartments would probably have a breakdown in the normal blood-ocular barriers, diminishing any partial privilege.

In the last decade, it has become increasingly clear that the adult mammal retains cells with the ability to divide and to become more than one final cell type. This defines them as 'stem' cells, and the first location in which they were studied in depth was the ependymal zone of the hippocampus. ${ }^{5}$ Recently, the ciliary body area of the rodent was found to contain cells that, on dissociation from the tissue and appropriate stimulation with growth factors, could divide extensively and could develop into cells with morphology and patterns of molecular expression characteristic of several retinal neuronal and glial species. ${ }^{6}$ We have now determined that such cells are present in the adult human ciliary body.

The importance of this finding is several fold. First, it becomes clear that the recipient can be the donor, through cyclectomy. This not only removes the ethical issues for the source, but simultaneously minimizes the likelihood of rejection. While one cannot be certain that donor cells that arise from the host ciliary body will retain their original HLA type, it is logical to assume that they are more likely to be viewed as self than any other tissue.

There is much work to be done in producing the needed RGC from ciliary body stem cells. The literature on development of RGC does provide clues on the molecular and genetic influences that would drive the relatively undifferentiated stem cell in the direction of RGC. ${ }^{7}$ The gene products of the MATH locus appear to be central to the development of RGC, and exposure to insulin is another stimulus to RGC production.

Considerable work will be needed to optimize this procedure and to prepare cells for placement into the eye. Our present work takes advantage of rodent models, particularly the transgenic mouse expressing Green Fluorescent Protein in all its cells. When stem cells are produced from the ciliary body of these animals, they continue to fluoresce, allowing easy distinction from host cells when they are injected into recipient eyes. With rodent models of glaucoma, we can inject stem cells into eyes with RGC removed by disease in a very similar fashion to that in ultimate human patients.

\section{Are RGC all that is needed?}

The studies of human, monkey, and rat eyes with glaucoma or an experimental glaucoma model have suggested that it is loss of RGC only that occurs in this disease. ${ }^{8-10}$ This would be fortunate for our restoration effort, as it would mean that only one cell type needs replacement. However, we have recently begun a major effort to assure that the glaucoma-damaged retina has indeed retained its other cell types. There is abundant evidence that the death of some neurons leads to the death of their partner cells by trans-synaptic degeneration and to the death of neighbouring cells of the same type by secondary degeneration. ${ }^{11}$ In retinitis pigmentosa, a gene defect in rhodopsin causes not only loss of rods, but death of cones (that express little or no rhodopsin), and alterations in other retinal neurons, as well as loss of some RGC. ${ }^{12}$

Even if the intraretinal partners of RGC are physically resident, it is not immediately obvious that they will be capable of re-establishing synapses with newly arrived neuronal precursors. We will need to re-establish synaptic connections between RGC and both amacrine and bipolar cells in appropriate patterns to generate the various signal pathways for colour, motion, and other retinal functions.

\section{Where should the new cells be placed ?}

It seems most probable that injection of new stem cells into the vitreous cavity would provide them access to their future, inner retinal location. Indeed, this route has already been utilized in some published reports, and we have used it in our work in rodents. To date, there is some evidence that intravitreally injected cells only enter the retina when a lesion has been made into the retinal surface. It is unclear whether the stem cells are unable to pass through the vitreoretinal interface, or whether the release of growth factors by retinal injury is facilitative to graft entry.

On the other hand, placement of hippocampal progenitor cells in the subretinal space leads to very impressive ingraftment of these cells into the retina and growth of axonal fibres towards and into the host optic nerve. It could be that the subretinal space is both partially privileged immunologically and serves more effectively to deliver the cells to the retina by confining them in a closed space immediately adjacent to the retina.

\section{How to guide growing axons to the lateral geniculate}

There is an increasing literature on the mechanisms by which growing RGC axons are directed to their targets in the brain. There are known chemoattractants and repellants that are present in the developing ocular tissues. ${ }^{13}$ It may be that the presence of 'fellow traveler' RGC axons is also an important stimulus for axon direction.

In this regard, the work of Aguayo and colleagues ${ }^{14}$ with transected optic nerve regeneration is highly relevant. For many years, it was believed that mammalian optic nerves responded to severe injury only 
with RGC degeneration and never with a successful regeneration. Yet, fish and amphibian eyes were shown to be able to respond to transection by growing a new and highly functional optic nerve. The hypothesis was proposed that the adult mammalian optic nerve could not regenerate through its degenerated distal portion due to inhibitory influences present there. Aguayo's group cut the rat optic nerve and sewed the stump that was connected to the eye to a segment of peripheral nerve. As many as $10 \%$ of the RGC grew an axon into the peripheral nerve graft. When the distal end of the graft was placed in the brain target zone (superior colliculus in the rat), anatomic synapses were demonstrated.

If we assume that it will be possible to obtain and to implant new RGC into the retina, we will need to provide a means for their growing axons to exit the eye and to arrive at the lateral geniculate body. ${ }^{15}$ It seems logical to use an approach based on the peripheral nerve graft. In the human, the sensory sural nerve has been routinely used in neurosurgical procedures for this purpose and lengths easily able to reach from eye to thalamus could be obtained. The morbidity would be limited to modest sensory loss on the leg surface that would be restored by regeneration.

The sural graft would not be placed at the original optic nerve head, as this would almost surely compromise the retinal and ciliary blood vessels. Rather, an opening in the sclera, choroid, and retina on the nasal side of the optic disc would be fashioned. One end of the sural nerve graft would be fixed through this opening. Its end projecting slightly into the eye would be treated with chemoattractants to draw growing axons from the stem cells. The other end of the graft would be placed in contact with the lateral geniculate body on the same side. We are presently engaged in studies that will determine if the best approach to this linkage will be deep through the brain substance, or externally around the brain and re-entering posterio-laterally.

\section{Are partner geniculate neurons still present?}

Studies of human brains from patients with glaucoma, as well as experimental monkeys show that there can be some loss of geniculate neurons in glaucoma. ${ }^{16,17}$

However, this loss appears to involve fewer than $20 \%$ of magnocellular neurons in human tissue and fewer than $40 \%$ of magnocellular neurons in monkeys. The critical parvocellular pathway seems to have minimal cell loss $(0-10 \%)$. As with the retinal zone, it will be important to re-establish synaptic connections between the new RGC and geniculate neurons. Perhaps the internal genetic programming of RGC will provide the needed steps for connection. It is possible, however, that the geniculate cells will be altered in a way that makes them refractory to reconnection.

\section{Will new circuitry provide visual perception?}

The complexity of the anterior visual pathway is such that we must be highly optimistic to believe that RGC growing in the adult, damaged substrate will be able to generate useful visual experiences of some kind. There are parallel situations that provide hope in this regard. Cochlear implant patients who had no functional hearing prior to their procedures do develop useful perception over time. ${ }^{18}$ It appears that the plasticity of the nervous system has been underestimated. However, in the experience of Low Vision specialists, many subjects are only happy when they are restored to visual function that is quite close to normal. For many persons, slight improvements, such as 'light perception' may be inadequate.

\section{Get serious}

It might be considered that the discussion to this point is merely a mind game. An after-dinner anecdote to stimulate the brain. Research is the ultimate mind game and brain stimulation is the endgame of this project. All of the pieces of this puzzle are within our reach, and in following this path, we are guaranteed to learn more about neuronal development, axon guidance, ocular immune responses, and visual perception. Those are topics that are highly fundable by national research groups. In contrast, someone who proposes to restore the optic nerve would be accused of high-risk behaviour and visionary dreaming.

Guilty.

\section{References}

1 Shamblott MJ, Axelman J, Wang S, Bugg EM, Littlefield JW, Donovan PJ et al. Derivation of pluripotent stem cells from cultured human primordial germ cells. Proc Natl Acad Sci USA 1998; 95: 13726-13731.

2 Castillo Jr B, del Cerro M, Breakefield XO, Frim DM, Barnstable CJ, Dean DO et al. Retinal ganglion cell survival is promoted by genetically modified astrocytes designed to secrete brain-derived neurotrophic factor (BDNF). Brain Res 1994; 647: 30-36.

3 Lund RD, Hankin MH. Pathfinding by retinal ganglion cell axons: transplantation studies in genetically and surgically blind mice. J Comp Neurol 1995; 356: 481-489.

4 Streilein JW, Masli S, Takeuchi M, Kezuka T. The eye's view of antigen presentation. Hum Immunol 2002; 63: 435-443.

5 Song HJ, Stevens CF, Gage FH. Neural stem cells from adult hippocampus develop essential properties of functional CNS neurons. Nat Neurosci 2002; 5(5): 438-445. 
6 Tropepe V, Coles BL, Chiasson BJ, Horsford DJ, Elia AJ, McInnes RR, van der Kooy D. Retinal stem cells in the adult mammalian eye. Science 2000; 287: 2032-2036.

7 Inoue T, Hojo M, Bessho Y, Tano Y, Lee JE, Kageyama R. Math3 and NeuroD regulate amacrine cell fate specification in the retina. Development 2002; 129: 831-842.

8 Quigley HA, Green WR. The histology of human glaucoma cupping and optic nerve damage: clinicopathologic correlation in 21 eyes. Ophthalmology 1979; 10: 1803-1827.

9 Frishman LJ, Shen FF, Du L, Robson JG, Harwerth RS, Smith EL et al. The scotopic electroretinogram of macaque after retinal ganglion cell loss from experimental glaucoma. Invest Ophthalmol Vis Sci 1996; 37: 125-141.

10 Kendell KR, Quigley HA, Kerrigan LA, Pease ME Quigley EN. Primary open-angle glaucoma is not associated with photoreceptor loss. Invest Ophthalmol Vis Sci 1995; 36: 200-205.

11 Levkovitch-Verbin H, Quigley HA, Kerrigan-Baumrind LA D'Anna S, Kerrigan DF, Pease ME. Optic nerve transection in monkeys may result in secondary degeneration of retinal ganglion cells. Invest Ophthalmol Vis Sci 2001; 42: 975-982.

12 Fariss RN, Li Z-Y, Milam AH. Abnormalities in rod photoreceptors, amacrine cells, and horizontal cells in human retinas with retinitis pigmentosa. Am J Ophthalmol 2000; 129: 215-223.

13 Oster SF, Sretavan DW. Connecting the eye to the brain: the molecular basis of ganglion cell axon guidance. Br J Ophthalmol 2003; 87: 639-645.

14 Vidal-Sanz M, Bray GM, Aguayo AJ. Regenerated synapses persist in the superior colliculus after the regrowth of retinal ganglion cell axons. J Neurocytol 1991; 20: 940-952.

15 Hallas BH, Lowe HF, Jacobsen G, LaCorte M, Lee SP, Zanakis MF. Developing retina and PNS segments for transplantation into the adult host eye: reconstruction of the mammalian visual system. 2. Results. J Neural Transplant 1989; 1: 87-93.

16 Weber AJ, Chen H, Hubbard WC, Kaufman PL. Experimental glaucoma and cell size, density, and number in the primate lateral geniculate nucleus. Invest Ophthalmol Vis Sci 2000; 41: 1370-1379.

17 Chaturvedi N, Hedley-Whyte ET, Dreyer EB. Lateral geniculate nucleus in glaucoma. Am J Ophthalmol 1993; 116: 182-188.

18 Giraud AL, Price CJ, Graham JM, Truy E, Frackowiak RS. Cross-modal plasticity underpins language recovery after cochlear implantation. Neuron 2001; 30: 657-663. 